University of Nebraska - Lincoln

DigitalCommons@University of Nebraska - Lincoln

Sociology Department, Faculty Publications

Sociology, Department of

1997

\title{
Psychological Distress and Help Seeking in Rural America
}

\author{
Dan R. Hoyt \\ University of Nebraska-Lincoln, dhoyt2@unl.edu \\ Rand D. Conger \\ lowa State University \\ Jill Gaffney Valde \\ lowa State University \\ Karen Weihs \\ George Washington University
}

Follow this and additional works at: https://digitalcommons.unl.edu/sociologyfacpub

Part of the Sociology Commons

Hoyt, Dan R.; Conger, Rand D.; Gaffney Valde, Jill; and Weihs, Karen, "Psychological Distress and Help Seeking in Rural America" (1997). Sociology Department, Faculty Publications. 73.

https://digitalcommons.unl.edu/sociologyfacpub/73

This Article is brought to you for free and open access by the Sociology, Department of at DigitalCommons@University of Nebraska - Lincoln. It has been accepted for inclusion in Sociology Department, Faculty Publications by an authorized administrator of DigitalCommons@University of Nebraska - Lincoln. 
Published in American Journal of Community Psychology 25:4 (1997), pp. 449-470.

Copyright ( 1997 Plenum Publishing Corporation. Used by permission.

http://www.springerlink.com/content/104830/

This article is based on research supported by the

National Institute of Mental Health (MH48165).

Corresponding author - D. R. Hoyt

\title{
Psychological Distress and Help Seeking in Rural America
}

\author{
Danny R. Hoyt, Rand D. Conger, and Jill Gaffney Valde \\ Iowa State University \\ Karen Weihs \\ George Washington University
}

\begin{abstract}
The implications of exposure to acute and chronic stressors, and seeking mental health care, for increased psychological distress are examined. Research on economic stress, psychological distress, and rural agrarian values each point to increasing variability within rural areas. Using data from a panel study of 1,487 adults, a model predicting changes in depressive symptoms was specified and tested. Results show effects by size of place for men but not for women. Men living in rural villages of under 2,500 or in small towns of 2,500 to 9,999 people had significantly greater increases in depressive symptoms than men living in the country or in larger towns or cities. Size of place was also related to level of stigma toward mental health care. Persons living in the most rural environments were more likely to hold stigmatized attitudes toward mental health care and these views were strongly predictive of willingness to seek care. The combination of increased risk and less willingness to seek assistance places men living in small towns and villages in particular jeopardy for continuing problems involving depressed mood.
\end{abstract}

Keywords: psychological distress, seeking mental health care

There is ample evidence that the economic and social dislocations associated with the 1980s farm crisis and related events have fundamentally impacted rural areas of the midwestern United States. Rural villages 
and small towns within this region have moved from the economic crisis of the past decade to a condition of chronic economic stagnation (Lasley, 1994; O'Hare, 1988). These places are increasingly characterized as lacking viable employment opportunities and experiencing increasing poverty rates (Bloomquist, Gringeri, Tomaskovic-Devey, \& Truelove, 1993, Duncan, 1992; Lichter, Johnston, \& McLaughlin, 1994; Tickamyer \& Duncan, 1990). These conditions have been described as marking the emergence of "America's Rural Ghetto" (Davidson, 1989). Poverty in some rural areas now approximates levels found in urban centers and there is a growing recognition of the ascriptive constraints on economic opportunity in rural places (Lichter \& McLaughlin, 1995; O'Hare \& Curry-White, 1992).

These economic and social dislocations in rural areas produce increased risk for psychological distress. Although persona! economic hardship is consistently found to be related to psychological distress (Catalano \& Dooley, 1977; Dohrenwend \& Dohrenwend, 1974; Kessler, Turner, \& House 1988; Pearlin, Lieberman, Menaghan, \& Mullin, 1981) there is also evidence of mental health outcomes associated with regional economic conditions (Catalano \& Dooley, 1981,1983). Research specific to the rural midwest has supported these findings. At the personal level, the stress induced by the economic and social upheaval of the 1980s produced short-term mental health impacts for farm operators (Armstrong \& Schulman, 1990). Other studies have provided evidence of broader mental health and related impacts encompassing both farm households and also residents in small towns and villages that serve the agricultural community (Conger \& Elder, 1994; Heffernan \& Heffernan, 1986; Hoyt, O'Donnell, \& Mack, 1995).

These trends reveal a rural environment that is increasingly diverse in terms of the financial status of persons and families and varied in the degree of personal resilience in the face of associated stressors. They directly challenge the myth that contemporary rural environments are homogeneous and well insulated from the types of stressors that increase risk for psychological distress (Wagenfeld, Murray, Mohatt, \& DeBryn, 1994). However, to this point, studies have predominantly examined these issues in the context of a single segment of the rural populace (e.g., farmers) or relied upon urban/rural comparisons which group a diverse set of non-metropolitan environments into a single rural category. This study examines the implications of exposure to acute and chronic stressors, and seeking mental health care, for psychological distress across a range of rural environments. We develop and test the hypothesis that persons living in rural villages and small towns will have greater increases in depressive symptoms over time than both persons living in rural areas outside of communities (rural farm and rural nonfarm households) and those living in larger places in this region (small cities and rural popula- 
tion centers). In addition, we examine variation across these places in the components of belief systems that are thought to influence the decision to seek professional mental health care in times of stress.

\section{Rural Economic Stress and Psychological Distress}

Research on rural stress and mental health in the past decade has emphasized the direct impacts of the farm crisis. Studies conducted during the peak of this crisis have documented the direct effects of economic hardship on farm operators and their families (Armstrong \& Schulman, 1990; Belyea \& Lobao, 1990; Bultena, Lasley, \& Geller, 1985). Subsequent analyses suggest that the direct mental health impacts are primarily short-term for farm residents. In a three-wave panel study of households in Nebraska, Ortega, Johnson, Beeson, and Craft (1994) found significant increases in depressive symptoms among farm households from 1981 to 1986 , but a decline to first-wave levels by 1989 . While not a primary focus of the analyses, their results suggest that the pattern of impact and recovery found among the rural farm households may not be experienced in other rural places.

These suggested variations in patterns of rural distress are paralleled by increased economic diversity across rural places (Lichter, 1993). There is a growing body of literature documenting the extent of poverty in rural areas (Brown \& Hirschl, 1995; Duncan, 1992). However, the trends in rural economic status are not uniform. In the 1980s, one fourth of the nonmetropolitan counties experienced substantial increases (3\% or more) in poverty, and $40 \%$ had decreasing levels of poverty (Lichter \& McLaughlin, 1995). The highest levels of rural poverty are found in counties in southern states, particularly among the African American segment of the rural population, and the greatest increases in the 1980s have been in rural areas that are adjacent to metropolitan places (Lahr, 1993). Farmer, Ilvento, and Luloff (1989) argue that poverty in rural areas may increasingly be defined in terms of structural features of rural places.

Consistent with the hypotheses of Catalano and Dooley (1981, 1983), recent research suggests that these local rural economic conditions are having mental health impacts that go beyond the effects of the direct personal stressors. Controlling for individual differences in economic stress and personal resources, Hoyt et al. (1995) found that residents of rural villages (2,500 or less) had significantly higher depressive symptoms than farm, rural nonfarm, and residents of larger small towns. The residents of these rural communities had levels of depressive symptoms, net of the effects of personal resources, that were not significantly different than those for residents of small cities and rural population centers. However, these findings should be interpreted with caution because they were based on 
cross-sectional data. In cross-section, the observed pattern of psychological distress could be produced by factors other than the differential impact of local economic conditions (e.g., selective drift of dislocated farmers into nearby rural villages). In the present study we overcome this limitation by using longitudinal data to consider how individual resources, personal economic circumstances, and characteristics of place combine to affect risk for changes in psychological distress over time.

\section{Agrarian Values and Help Seeking}

There is evidence that the economic restructuring being experienced in the midwest is also influencing basic attitudes and values of rural residents. The agrarian ideology that has been viewed as characteristic of rural places in this region emphasizes independent male producers, conservatism, self-reliance, and close-knit ties among neighbors (Sachs, 1983; Wilkinson, 1991). However, the economic crisis has brought a number of fundamental changes to the social fabric of rural places. There has been a significant increase in off-farm employment, particularly on the part of rural women, and increased ethnic diversity associated with new lowwage industries (Bokemeier \& Tickamyer, 1985; Lamphere, 1992). Combined with the general upheaval associated with the farm crisis, these shifts in rural economic and social structure have introduced variability in persons and experiences that serve to challenge the traditional agrarian ideology (Naples, 1994).

The values associated with the agrarian ideology have been linked to reluctance to make use of mental health services. In particular, the emphasis on self-reliance and rugged independence are not conducive to seeking formal care (Buckwalter, Smith, Zevenbergen, \& Russell, 1991; Coward, DeWeaver, Schmidt, \& Jackson, 1983; Hendricks \& Turner, 1988). Moreover, in conjunction with these values, the smaller and more intimate nature of rural environments may produce a lessened sense of confidentiality and increased pressure to conform (Nease, 1993). Rost, Smith, and Taylor (1993) found that the more negative the labeling associated with seeking mental health care, the less likely rural residents with histories of depressive symptoms were to have sought professional help. While there has been some research to the contrary (Flaskerud \& Kviz, 1982), the findings generally provide support for the notion that values more typical of rural residents tend to influence both the definition of mental health problems and the probability of seeking help (Flax, Wagenfeld, Ivens, \& Weiss, 1979; Wagenfeld \& Wagenfeld, 1981). The present study considers the influence of the farm crisis and subsequent economic trends on the perceptions of mental health care, and willingness to seek care, using a contemporary longitudinal sample from a rural midwestern state. 


\section{Psychological Distress Across Rural Places}

The research findings on economic stress, psychological distress, and agrarian values all point to increasing diversity within rural regions. Accordingly, a number of considerations lead us to hypothesize differential effects on psychological distress and help-seeking behaviors across segments of the rural population. First, the economic decline and associated stressors are expected to have direct impacts that vary across rural places. The acute crisis in the 1980s farm economy has evolved into a chronic condition affecting the surrounding rural communities (Lasley, 1994). In contrast to the improvement of the economic situation for the farmers who remained in business, and the less direct exposure and impact in larger cities and rural population centers, residents of small rural communities face a number of persistent economic and social challenges. Many of these challenges relate to the fact that, although the economic situation of farmers has generally improved, there are fewer farm operators today than a decade ago and their numbers continue to decline. Thus, the rural villages and small towns continue to lose the clientele they have traditionally served. Moreover, these small rural places tend to lack the human capital and other strategic resources to develop new economic partners to replace the traditional markets that they have lost. Accordingly, we hypothesize that persons living in rural villages and small towns will have higher levels of psychological distress than farm, rural nonfarm, and residents of larger rural population centers.

Second, in addition to this direct effect we hypothesize differential effects of stressors across place, where the impact will be greater in rural villages and small towns. This is a differential vulnerability hypothesis similar to those in stress-distress literature that address race or gender contrasts (Kessler \& McLeod, 1984; Ulbrich, Warheit, \& Zimmerman, 1989). It is in the rural villages and small towns that traditional values have been most disrupted and typical feelings of community attachment most affected (O'Brien, Hassinger, \& Dershem, 1994). The loss of local schools, churches, and other community-based organizations has become increasingly common in these rural places. These changes are likely to diminish the types of community support that has typically helped to buffer adverse experiences. Thus, net of personal resources, persons living in rural villages and small towns are expected to have a greater vulnerability to stressors than residents of rural farms and those persons living in larger places.

The bases for predicting variation in attitudes toward mental health care are less clear. Research linking rural attitudes and values to mental health service use is almost exclusively focused on rural/urban differences, providing little insight into potential variation within rural areas. 
Recent research suggests that the traditional agrarian ideology is becoming less typical in rural communities (Naples, 1994) whereas it may be more resistant to change among farm residents. Since persons who hold these views are less likely to make use of services, we expect an emergence of differences in attitudes toward mental health between farm residents and persons in rural villages and small towns. Compared to small cities and rural population centers, the rural places with low population density continue to be characterized by a lessened sense of confidentiality that is likely to contribute a heightened stigma toward mental health care. This stigma, in turn, is expected to lead to decreased willingness to seek mental health care. Combined, these factors should contribute to significant place variation in attitudes toward mental health care. Specifically, we hypothesize that stigma toward, and the reluctance to use, formal mental health services will be strongest in farm and rural nonfarm areas and will decrease with increasing size of place.

\section{Methods}

\section{Sample}

The data used in this analysis are from the Iowa Health Poll, a longitudinal survey of health and mental health needs and service use. In 1992 a total of 2,406 adults were interviewed by telephone in a statewide sample designed to provide rural/urban variation. Households were randomly sampled and, within households, the respondent was randomly selected from the pool of eligible adults residing in the residence full time. The response rate was $76.3 \%$. A little over 1 year later, the research team was able to locate $90.1 \%$ of the original sample and $80.0 \%$ of these agreed to participate in the interview. A total of 1,735 persons were reinterviewed in the follow-up study, representing $72.1 \%$ of the original sample. The initial wave of data collection included some variations in questionnaire format and items that are being used to examine methodological issues in rural surveys (Lorenz, Saltiel, \& Hoyt, 1995). In the present study the base sample comprised the 1,487 adults who were administered the full battery of mental health questions in both waves of data collection.

One unique characteristic of this sample is the occurrence of the 1993 floods between the first and second wave of data collection. The entire state of Iowa was declared a disaster area in July 1993 due to severe flooding. This natural disaster provided a unique opportunity to further examine the nature of the stress-distress relationship. In addition to looking at chronic economic stressors, this sample provided the opportunity to include measures of acute stress associated with exposure to the flooding. 


\section{Measures}

The dependent variable in the initial model, psychological distress, is measured using the Center for Epidemiological Studies Depression Scale (CES-D, Radloff, 1977). Designed for community samples, it measures current level of depressive symptoms. Each item has a 4-point response format regarding the presence of a particular symptom during the past week: 0 (rarely or none of the time, 1 day), 1 (some or a little of the time, 1-2 days); 2 (occasionally or a moderate amount of time, 3-4 days), and 3 (most or all of the time, 5-7 days). The scale has a possible range of 0 to 60 . The CES$\mathrm{D}$ has been demonstrated to be useful as a tool in assessing depressive symptoms across populations and has been used to examine depression in a rural context (Husaini, Neff, Harrington, Hughes, \& Stone, 1980) The mean score for the CES-D in this sample was 7.94 at the first measurement and 7.81 when measured a year later. The alpha reliability is .90 for the Time I measure and .89 at the second time point.

There are three measures of individual-level stress. Financial stress is measured through a series of four questions. The respondents are asked to indicate if they had experienced each of the economic problems indicated by the questions in the prior 12-months. The economic hardship measures include having a substantial decrease in income, having trouble paying bills on time, being laid off at work, and having to use savings to meet expenses. The number of affirmative responses are summed to create a financial stress scale with a potential range of 0 to $4(\mathrm{M}=0.72, \mathrm{SD}=0.97)$. One concern with this indicator is that it could be differentially valid across our study groups. In particular, the financial realities of self-employed farmers might make it less likely that they would report being laid off at work. To address the potential problem of underadjusting for financial stress experienced within selected subgroups, we replicated the basic analyses reported in this paper using three indicator variations on this scale. These analyses did not produce any substantive differences from the results reported here. Personal stress was measured as a sum of four stressful life events. The items asked if in the past year the respondent had someone in the house who was seriously ill or injured, had a close friend or relative die, had something stolen from the house, or had broken up with spouse. The number of affirmative responses are summed to create a personal stress scale with a potential range of 0 to $4(\mathrm{M}=0.77, \mathrm{SD}=0.80)$. The final stress measure is a summed index of losses experienced due to the flood of 1993. These flood loss items inquired about loss or damage to personal items, home, property, and any income loss associated with employment or business activities. The summed items had a potential range of 0 to $4(\mathrm{M}=0.21, \mathrm{SD}=0.65)$. 
Size of place is operationalized into six categories that represent important distinctions in the context of the economics and demographics of the study region (Hoyt et al., 1995, Johnson \& Ortega, 1994), farm households, rural nonfarm households, rural villages (under 2,500 population), small towns $(2,500$ to 9,999$)$, small cities $(10,000$ to 49,999$)$, and rural population centers (50,000 and larger). Consistent with the shifting demography of this region, over one third $(36.9 \%)$ of the persons reside in rural population centers with relatively balanced distributions across the other size of place categories (farm, 10.0\%; rural nonfarm, $8.5 \%$; rural villages, $15.4 \%$; small town, $14.9 \%$; small city, $14.2 \%)$. We use the term rural population center because these metropolitan areas are located in a state with an economy that is predominantly agriculturally based. As such, these larger places may best be conceived as rural population centers that are in many respects distinct from larger metropolitan centers in other regions. This largest population aggregation is used as the reference category for the dummy regression measures for size of place.

Personal resources are measured using indicators of perceived social support and sense of control. Social support is measured using two indicators developed by Ross and Huber (1985). The questions tapped the extent to which the respondents reported that they have someone to talk to and there is someone who they can turn to for support. Each item was measured on a 1 (strongly disagree) to 4 (strongly agree) response format. The scale is computed by summing and dividing by the number of items (potential range 1 to $4, \mathrm{M}=3.41, \mathrm{SD}=0.63$ ). The alpha reliability is .85 for this measure. Sense of control is measured using the scale developed by Mirowsky and Ross (1989). This is an eight-item balanced scale indicating instrumental and fatalistic responses to both good and bad outcome dimensions. For example, a fatalistic response to a good outcome would be indicated by the statement "the really good things that happen to me are mostly luck." Each item was measured on a 1 (strongly agree) to 4 (strongly disagree) response format. The scale is calculated by summing and dividing by the number of items (range 1 to $4, \mathrm{M}=3.03, \mathrm{SD}=0.33$ ). The scale items have an alpha reliability of .65.

The models to be tested each include basic demographic measures that have shown consistent associations with the dependent variables in the models (Dean \& Ensel, 1982; Kessler, 1982; Kessler, Price, \& Wortman, 1985; Mirowsky \& Ross, 1989; Newman, 1989). Age is coded as an ordinal measure with seven categories $(\mathrm{M}=4.13, \mathrm{SD}=1.65)$. Education is also coded as an ordinal measure representing highest degree obtained (range $1-7, \mathrm{M}=3.41, \mathrm{SD}=2.01)$. Income is coded as an ordinal measure, with 10 income categories in increments of $\$ 5,000(\mathrm{M}=6.04, \mathrm{SD}=2.20)$. Health limitations are measured using a sum of six questions on types and ex- 
tent of health limitations $(\mathrm{M}=1.09, \mathrm{SD}=0.91)$. This scale covered a range of activities from having limitations performing vigorous activities, such as lifting heavy objects, to needing help getting around one's home. Marital status is coded as a married-not married dichotomy (68\% married) and gender as a dummy variable with females as the reference category (female, 64\%; male, 36\%).

Prior mental health service use is measured with a single item that asked if the respondent had sought any help for an emotional or mental health concern from a "mental health professional" in the past year (dummy coded $1=$ Yes, $\mathrm{M}=0.06, \mathrm{SD}=0.23$ ). Willingness to seek help from a mental health professional is developed from two indicators that measure the likelihood of going for help with a "serious emotional problem" and how willing they are to talk to a professional about "personal problems." The alpha reliability coefficient for these two measures is .65. The scale was computed as the mean response to the two questions with a resulting range from 1 to $4(\mathrm{M}=3.01, \mathrm{SD}=0.80)$.

Stigma toward mental health services is measured using a weighted indicator. Two items tapped the degree to which a respondent would be embarrassed if either friends or other persons in the community found out that they were getting professional mental health help were averaged (range of 1 to 4). This measure was then weighted by a measure representing how likely persons felt it would be for others in their community to find out that they were getting professional mental health care (range 1 to 4$)$. The resulting stigma measure has a potential range of 1 to 16 , with the highest values representing respondents who feel that getting help is embarrassing and that persons in the community would find out about any care they might receive $(\mathrm{M}=8.10, \mathrm{SD}=3.42)$.

\section{Results}

The distributions of the three stressor and two personal resource variables across size of place are presented in Table I. For two of the three indicators of stress, flood loss and personal stress, there were no significant differences across size of place. There were significant differences for financial stress, with the greatest levels of stress reported by farm residents, followed by persons living in rural villages and small towns. Thus, to the extent that there are stress differences across place, they do show some rural disadvantage but do not support the relative improvement predicted for farm households.

The results for the base distribution of social support across size of place do not show any significant variation across place. However, there are differences for sense of control. Persons living in rural villages and on 
Table I. Mean Differences in Stress and Personal Resources Across Rural Places

\begin{tabular}{lccccc}
\hline Size of place & $\begin{array}{c}\text { Financial } \\
\text { stress }\end{array}$ & $\begin{array}{c}\text { Personal } \\
\text { stress }\end{array}$ & $\begin{array}{c}\text { Flood } \\
\text { loss }\end{array}$ & $\begin{array}{c}\text { Social } \\
\text { support }\end{array}$ & $\begin{array}{c}\text { Sense of } \\
\text { control }\end{array}$ \\
\hline Farm & .87 & .70 & .16 & 3.50 & 2.99 \\
Rural, nonfarm & .66 & .71 & .14 & 3.36 & 3.06 \\
Rural village & .73 & .75 & .20 & 3.39 & 2.98 \\
Small town & .71 & .72 & .20 & 3.39 & 3.05 \\
Small city & .61 & .72 & .28 & 3.46 & 3.09 \\
Rural population center & .58 & .81 & .24 & 3.39 & 3.08 \\
F test & 2.625 & 0.832 & 1.203 & 1.392 & 4.439 \\
Significance & .023 & .527 & .305 & .224 & .001 \\
\hline
\end{tabular}

farms, on the average, reported lower levels of sense of control than persons residing in other places. In sum, the zero-order distributions of the stress and personal resource variables across size of place show either no, or relatively modest, differences.

\section{Predicting Women's Psychological Distress}

Given the extensive literature documenting gender differences in patterns and predictors of depressive symptoms, each of the multivariate models was initially estimated separately for women and men. These analyses indicated substantial contrasts across the models and, thus, the results of the analyses are reported separately by gender. The initial set of models uses linear regression to predict depressive symptoms at the second interview controlling for prior symptoms. For each model we conducted additional analyses to detect potential difficulties associated with outliers and influential data points. Additional tests were performed and reported for any models in which these types of factors had significant influences on parameter estimates.

Since these models control for prior levels of depressive symptoms, they are effectively addressing change in symptom levels between the first and second waves of data collection. As expected in this type of analysis, prior level of depressive symptoms is a significant predictor of current symptom level in each of the estimated models. Controlling for earlier symptom levels, the initial model for women shows significant effects for three of the four personal demographic variables (Table II, Model 1). Older age $(b=-1.02)$ was associated with lower Time 2 depressive symptoms. Health limitations had a significant positive association, the more the limitations the greater the increase in depressive symptoms $(b=0.96)$. Married women had significantly smaller increases in depressive symptoms than nonmarried respondents $(b=-1.40)$. Finally, higher levels of income were associated with lower symptoms $(b=-0.37)$. 
Table II. Regression Model for Time 2 Depressive Symptoms for Women

\begin{tabular}{|c|c|c|c|c|c|c|}
\hline \multirow[b]{2}{*}{ Independent variables } & \multicolumn{3}{|c|}{ Model 1} & \multicolumn{3}{|c|}{ Model 2} \\
\hline & $b$ & $\beta$ & $p$ & $b$ & $\beta$ & $p$ \\
\hline CESD Time 1 & 0.45 & .44 & .000 & 0.48 & .47 & .000 \\
\hline Age & -1.02 & -.17 & .000 & -1.00 & -.16 & .000 \\
\hline Health limits & 0.96 & .10 & .043 & 0.87 & .09 & .006 \\
\hline Marital status & -1.40 & -.07 & .051 & -1.51 & -.08 & .033 \\
\hline Education & 0.03 & .01 & .857 & 0.03 & .01 & .877 \\
\hline Income & -0.37 & -.09 & .024 & -0.39 & -.09 & .017 \\
\hline \multicolumn{7}{|l|}{ Size of place } \\
\hline Farm & -1.78 & -.05 & .128 & -1.69 & -.05 & .142 \\
\hline Rural, nonfarm & -1.08 & -.03 & .335 & -0.91 & -.03 & .413 \\
\hline Rural village & -1.59 & -.06 & .079 & -1.43 & -.06 & .112 \\
\hline Small town & -1.39 & -.05 & .117 & -1.30 & -.05 & .138 \\
\hline Small city & -0.07 & .00 & .934 & 0.14 & -.01 & .873 \\
\hline Flood loss & 0.96 & .08 & .018 & 0.98 & .08 & .014 \\
\hline Personal stress & 0.51 & .04 & .178 & 0.46 & .04 & .223 \\
\hline Financial stress & 1.01 & .11 & .001 & 0.94 & .10 & .002 \\
\hline Social support & -0.58 & -.04 & .218 & -0.57 & -.04 & .217 \\
\hline Sense of control & -2.65 & -.09 & .007 & -2.61 & -.09 & .007 \\
\hline MH help & & & & 7.04 & .20 & .000 \\
\hline Help $\times$ CESD interaction & & & & -0.31 & -.16 & .003 \\
\hline Constant & 19.54 & & & 19.13 & & \\
\hline$R^{2}$ & .397 & & & .411 & & \\
\hline
\end{tabular}

Experience with financial stress $(b=1.01)$ was associated with significant increases in depressive symptoms for women. The acute stress of exposure to losses associated with the flooding also had a significant impact $(b=0.96)$ where higher exposure predicted increased depressive symptoms. Personal stress exposure was not related to increases in depressive symptoms for the female respondents.

Controlling for differences in personal demographic variables and stressors, the analysis showed only one marginal direct effect for size of place. Using the large rural population centers as the reference contrast, women living in rural villages had a marginally significant $(b=-1.59, p=$ .079) difference in levels of depressive symptoms. Significance levels between .05 and .10 are sufficient for a one-tail significance test. However, since the direction of this effect was opposite of our predictions, it does not support our hypotheses. These contrasts suggest lower increases in depressive symptoms for women in rural villages than for their larger city counterparts. 
The next set of independent variables are measures of social and personal resources. Contrary to expectations, perception of social support did not demonstrate an association with Time 2 depressive symptoms. Sense of control had the anticipated association of higher levels of control predicting lower symptom levels $(b=-2.65)$.

Analyses were conducted to examine possible interactions between size of place and each set of stressors. There were no significant interactions for either personal or financial stressors. There were two marginally significant interactions (women in small towns and in small cities) for size of place with the acute stress associated with flood losses. However, diagnostic analyses indicated that these interactions were produced by a couple of influential data points and did not maintain after corrections were introduced for the outliers. Thus, there is no support for differential vulnerability to stressors by size of place for women.

Model 2 in Table II addresses the potential impact of having sought mental health services. The introduction of the service-related measures had minimal impact on the associations observed in the base model. With the exception of the marginal size-of-place effect for rural villages, each of the relationships that were significant in the initial model remained so in the second model. Seeking formal mental health services was associated with an increased level of depressive symptoms. Women who had sought help from a mental health professional had a significantly higher level of Time 2 depressive symptoms $(b=7.04)$.

The results from this model also suggest that seeking help from a mental health professional produced positive effects. The interaction between seeking help and Time 1 symptoms $(b=-.31)$ was significant. Since service use was dummy coded, this coefficient represents the adjustment to the slope between Time 1 depressive symptoms and Time 2 symptoms. Thus, the slope for Time 1 depression for women who sought help was 17 compared to .48 for women who did not seek help. These results suggest that seeking mental health services helps to buffer the impact of prior depression.

Tests for potential interactions between size of place and help seeking did not produce any significant effects. Similarly, the three-way interactions between size of place, help seeking, and time 1 depressive symptoms were not significant. Accordingly, there is no evidence that either seeking mental health services, or the buffering impact of this behavior, varies across place for women.

\section{Predicting Men's Psychological Symptoms}

Table III summarizes the results of the same models for men. Consistent with the findings for women, Time 1 depressive symptoms in Model 1 are significantly related to Time 2 symptoms $(b=0.50)$. However, 
Table III. Regressions Model for Time 2 Depressive Symptoms for Men

\begin{tabular}{|c|c|c|c|c|c|c|}
\hline \multirow[b]{2}{*}{ Independent variables } & \multicolumn{3}{|c|}{ Model 1} & \multicolumn{3}{|c|}{ Model 2} \\
\hline & $b$ & $\beta$ & $p$ & $b$ & $\beta$ & $p$ \\
\hline CESD Time 1 & 0.50 & .44 & .000 & 0.47 & .41 & .000 \\
\hline Age & -0.53 & -.10 & .034 & -0.60 & -.11 & .018 \\
\hline Health limits & -0.01 & .00 & .989 & -0.03 & .00 & .951 \\
\hline Marital status & -0.62 & -.03 & .493 & -0.35 & -.02 & .694 \\
\hline Education & -0.29 & -.08 & .094 & -0.31 & -.09 & .066 \\
\hline Income & 0.01 & .00 & .951 & 0.01 & .00 & .956 \\
\hline \multicolumn{7}{|l|}{ Size of place } \\
\hline Farm & 0.17 & .01 & .890 & 0.29 & .01 & .817 \\
\hline Rural, nonfarm & -1.71 & -.06 & .176 & -1.58 & -.06 & .205 \\
\hline Rural village & 1.69 & .07 & .107 & 1.89 & .08 & .069 \\
\hline Small town & 2.48 & .11 & .016 & 2.17 & .10 & .034 \\
\hline Small city & -0.41 & -.02 & .700 & -0.55 & -.02 & .611 \\
\hline Flood loss & 1.03 & .10 & .022 & 1.06 & .10 & .017 \\
\hline Personal stress & 1.59 & .17 & .000 & 1.52 & .16 & .000 \\
\hline Financial stress & 1.20 & .14 & .002 & 1.07 & .12 & .006 \\
\hline Social support & -0.47 & -.04 & .395 & -0.37 & -.03 & .493 \\
\hline Sense of control & -0.13 & -.01 & .906 & -0.10 & .00 & .918 \\
\hline MH help & & & & 12.25 & .27 & .031 \\
\hline Help $\times$ CESD interaction & & & & -0.38 & -.14 & .026 \\
\hline Constant & 6.61 & & & 6.57 & & \\
\hline$R^{2}$ & .380 & & & .394 & & \\
\hline
\end{tabular}

among the personal demographic variables, only age has a statistically significant effect $(b=-0.53)$. Increased age was associated with decreased symptoms. Each type of stress demonstrated significant effects. Personal stress $(b=1.59)$, financial stress $(b=1.20)$, and flood loss $(b=1.03)$ were associated with significant increases in depressive symptoms for men.

Men living in small towns $(2,500$ to 9,999$)$ had significantly higher symptoms than those living in rural population centers. Controlling for differences in personal demographic variables and stressors, men in small towns had an average symptom score that was 2.48 higher than the score for men in the rural population centers. Consistent with the findings for women, there were no significant interactions between the various stressors. The two measures of social and personal resources, perceived social support and sense of control, were not related to Time 2 depressive symptoms.

The introduction of the measures of seeking mental health services and the interaction of this behavior with prior depressive symptoms in Model 2 produced some variation from the results in the initial model. The introduction of service use measures produced a marginally signifi- 
cant effect for men residing in rural villages $(b=1.89, p=.069)$. Men living in towns still had levels of depressive symptoms that were significantly different from the larger rural population centers. In both instances, the differences were in the predicted direction of higher symptom levels in the smaller places.

Consistent with the results from Model 1, each of the measures of stress remained significant. Seeking formal mental health services was associated with higher levels of depressive symptoms $(b=12.25)$ at Time 2. Similar to the results for the women's models, the interaction between seeking help and Time 1 symptoms was significant. The slope for Time 1 depression for men who sought help was .38 lower than the estimate for men who did not seek help. As before, the tests for potential interactions between size of place and help seeking and the three-way interactions between size of place, help seeking, and Time 1 depressive symptoms did not produce any significant effects. There is no evidence that patterns and outcomes of seeking mental health services varies across place for men.

The data for men and women were combined and tests for the direct and interaction effects of gender were estimated. There were no significant direct effects of gender, but as might be anticipated from the regression analyses reported for the separate gender models, there were a few significant interactions. Two of these interaction effects were for size of place. The large positive parameters for men living in rural villages and small towns were significantly different from the small negative estimates generated in the women's model. One other gender interaction was indicated where the buffering effect of sense of control was significantly larger (i.e., negative) for women than for men.

\section{Predicting Mental Health Beliefs}

The final models address the predictors of stigma toward, and willingness to seek, mental health treatment. As with the prior models, these analyses were initially performed separately for men and women. In this instance, there were relatively few contrasts across the models, so the analyses were combined and tests for gender interactions were conducted where appropriate. The first stage of this analysis examined stigma toward mental health care (Table IV, first set of columns). The only personal demographic variable significantly related to stigma was age. The older the respondent, the lower their stigma toward mental health care $(b$ $=-.15)$. Gender, health limitations, marital status, and education did not show any systematic association with mental health care stigma.

There was some support for the hypothesized influence of social support on levels of stigma. Higher levels of perceived social support were 
Table IV. Regressions Predicting Stigma and Attitudes Toward Seeking Mental Health Care

\begin{tabular}{|c|c|c|c|c|c|c|}
\hline \multirow[b]{3}{*}{ Independent variables } & \multicolumn{6}{|c|}{ Dependent variables } \\
\hline & \multicolumn{3}{|c|}{ Stigma } & \multicolumn{3}{|c|}{ Help seeking } \\
\hline & $b$ & $\beta$ & $p$ & $b$ & $\beta$ & $p$ \\
\hline Gender & -0.20 & -.03 & .407 & 0.23 & .14 & .000 \\
\hline Age & -0.15 & -.07 & .057 & 0.09 & .18 & .000 \\
\hline Health limits & 0.09 & .02 & .504 & 0.02 & .02 & .538 \\
\hline Marital status & 0.36 & .04 & .195 & 0.07 & .04 & .299 \\
\hline Education & -0.03 & -.02 & .636 & 0.02 & .05 & .169 \\
\hline Income & -0.02 & -.01 & .715 & 0.00 & .00 & .981 \\
\hline \multicolumn{7}{|l|}{ Size of place } \\
\hline Farm & 2.32 & .20 & .000 & 0.13 & .05 & .187 \\
\hline Rural, nonfarm & 1.58 & .14 & .000 & 0.15 & .06 & .104 \\
\hline Rural village & 2.28 & .25 & .000 & 0.09 & .06 & .230 \\
\hline Small town & 1.72 & .19 & .000 & 0.15 & .07 & .058 \\
\hline Small city & 0.89 & .09 & .010 & 0.10 & .04 & .222 \\
\hline Social support & -.36 & -.07 & .050 & 0.13 & .11 & .002 \\
\hline Sense of control & 0.48 & .04 & .208 & 0.23 & .09 & .008 \\
\hline CESD & 0.05 & .13 & .000 & -0.01 & -.08 & .034 \\
\hline Prior MH help & 0.50 & .04 & .660 & 0.52 & .17 & .000 \\
\hline Gender $\times$ Prior $\mathrm{MH}$ & -2.44 & -.16 & .046 & & & \\
\hline Stigma & & & & -0.02 & -.11 & .001 \\
\hline Constant & 4.37 & & & 1.31 & & \\
\hline$R^{2}$ & .094 & & & .106 & & \\
\hline
\end{tabular}

associated with lower levels of stigma $(b=-0.36)$. Contrary to expectations, sense of control was not associated with stigma toward mental health services.

As predicted, persons in rural places expressed significantly higher levels of stigma than residents of population centers. The magnitude of the differences in the stigma scale ranged from a contrast of 0.89 for residents of small cities to 2.32 for persons in villages. All of the contrasts were statistically significant, and all were in the direction of higher levels of stigma for persons living in a variety of rural environments. Although not directly tested, there appears to be a general pattern of smaller contrasts for the larger rural locations (small cities) and greater contrasts for rural villages and farms. The contrast of 1.58 for rural nonfarm likely reflects the heterogeneity of this category, including both relatively wealthy country commuters and the displaced rural poor.

Consistent with the research literature, persons with higher levels of depressive symptoms were more likely to have a stigmatized view of mental health services $(b=0.05, p=0.000)$. Prior use of a mental health 
professional was associated with significantly lower levels of stigma for women but not for men. Given the dummy coding used for both gender and prior mental health services, the interaction term for gender by prior mental health services $(b=-2.44)$ indicates that women who have previously received help are substantially less likely than either men or women who have not received services to hold stigmatized views.

The second stage of analysis in this model, presented in the second set of columns in Table IV, considers the predictors of willingness to seek mental health care. Two of the demographic variables were significantly related to this attitude measure. Women are more likely than men to indicate a willingness to seek mental health care $(b=0.23)$. Older respondents $(b=0.09)$ likewise are more willing to seek help in this domain.

Higher levels of personal resources were associated with an increased likelihood of seeking mental health services. The greater the perception of social support, the more willing to seek services when in need $(b=0.13)$. There was also a significant association for sense of control $(b=0.23)$ indicating that persons who are higher on this personal resource dimension were more likely to be willing to seek professional help.

Contrary to expectations, there was little evidence of a pattern of association between size of place and willingness to seek mental health services. One size-of-place contrast was marginally significant, with higher levels of willingness to seek help among residents of small towns $(b=$ $0.15, p=0.058)$. The other size-of-place contrasts, while nonsignificant, were also in the positive direction. Thus, to the extent that these data display any size- of-place pattern, it is the opposite of the predicted effect. As noted by one of our reviewers, this pattern may be complicated by potential differences across place in how persons define serious emotional problems. If this is the case, then we could be looking at willingness to seek help for different sorts of mental health problems. The data used in these analyses do not include measures that permit us to examine this possibility.

Prior mental health symptoms and service use were each related to future willingness to seek help from a mental health professional. Higher levels of depressive symptoms were associated with a decreasing interest in seeking formal assistance for mental health problems $(b=-0.01, p$ $=0.034$ ). On the other hand, prior experience with seeking help from a mental health professional was significantly associated with an increased willingness to seek help, if needed, in the future $(b=0.52)$.

As predicted, stigma toward mental health service use was strongly associated with willingness to seek mental health services in the future. The greater the stigma, the less likely the respondent was to indicate an interest in seeking future formal assistance $(b=-0.02, p=0.001)$. Thus, the 
effects of rural residence on willingness to seek help operate indirectly, via stigmatized attitudes regarding mental health care.

\section{Discussion and Conclusions}

These results demonstrate the importance for research to address variation within rural environments. Although not all of the hypothesized effects were confirmed, the findings do show main effects on changes in depressive symptoms by size of place for males. Net of personal stressors and resources, men living in rural villages and small towns were significantly more likely to have increases in depressive symptoms than men living on farms or in larger population centers. These findings support the main effect of size of place. The results are consistent with community-level effects linked to local economic context (Catalano \& Dooley, 1983), impact of community decline and loss of attachment ( $\mathrm{O}^{\prime}$ Brien et al., 1994, Wright \& Rosenblatt, 1987), or some heterogeneity in stressors across place not considered in this model. There were no significant interactions between size of place and stressors for men. Thus, there is no support for the differential vulnerability hypothesis, which predicted stronger impacts of the stressors on depression among residents of rural villages and small towns.

There was no support for the hypothesized direct effect of size of place, nor the interaction of stressors with size of place, for women. In a departure from the findings for men, women in rural villages and small towns were not any more likely than women who live in rural population centers to experience changes in depressive symptoms. It should be noted, however, that the lack of significant differences across size of place is also not supportive of the long-held notion of small rural places somehow insulating their residents from the types of stressors thought to increase psychological distress in larger towns and cities. In other words, women living on farms and in rural villages were just as likely as their rural population center counterparts to experience increases in depressive symptoms. Combined, the findings for men and women underscore the importance of recognizing that the need for prevention and treatment efforts in rural places has not declined in the aftermath of the farm crisis.

What types of factors might account for the differences in the size-ofplace findings across gender? The significant gender differences appear in the rural villages and small towns, both types of places where we anticipated maximum impact of the stressors associated with the changing rural economic landscape. As noted, this is also where the rugged independence and male provider norms associated with agrarian values are deeply held, particularly on the part of rural men. To the extent that persons in these 
areas are encountering stressors that are upsetting the traditional system (e.g., having to take on multiple jobs, both husband and wife employed out of the home), the impacts on increasing depressive symptoms may be stronger for the men. Just as we noted that the financial stress indicators could be differentially valid across place, it may be important to replicate these gender findings using a more comprehensive inventory of potential stressors. This would help distinguish between potential gender biases in the stressor lists and differential vulnerability by gender.

If commitment to the agrarian value system varies by gender in the manner described above, it could also help account for two other genderrelated findings. The interaction by gender for the impact of prior mental health treatment on stigma indicates that men are more likely than women to hold stigmatized views toward mental health following treatment. It may be, that seeking this type of assistance is viewed as particularly embarrassing for persons who value self-reliance and rugged individualism. This same set of values would also be consistent with the observed gender differences in willingness to seek mental health care. At a minimum, future research should consider these and other possible factors to further examine these intriguing gender differences in the predictors of stigma and willingness to seek care. If confirmed by subsequent investigations, these findings could have important implications for the design and delivery of prevention and treatment programs targeted to men and women in rural areas.

The results show important size-of-place variation in stigma toward mental health care. Consistent with the hypothesis, the primary contrasts between the large population centers and each of the smaller places were significant and in the predicted direction. Both men and women living in the smaller places had significantly higher levels of stigma. Although not directly tested, the pattern of the effects indicates the highest levels of stigma among farm and rural village residents. An analysis of the components of the stigma measure provides some context for these findings. The base distributions of the embarrassment items shows less variation across place than the likelihood of others in the community finding out about mental health visits. Thus, it is the particular combination of potential feelings of embarrassment with heightened sense of lack of privacy that differentiate the smaller places from the larger population centers. The final model provides evidence that this stigma is a significant factor in the attitudes that influence help-seeking behaviors. It is important to note that once stigma is introduced into this model, there are no size-of-place effects on attitudes toward seeking mental health care. Thus, size of place operates primarily in the context of a lessened sense of privacy and confidentiality leading to stigma. In effect, stigma appears to operate as a moderator variable between size of place and willingness to seek mental health care. 
The finding on the effects of seeking help from a mental health professional is encouraging. For both men and women, there is a significant interaction effect between seeing a mental health professional in the past year and prior levels of depressive symptoms. The direction of this effect indicates that seeking help buffers the effects of prior depression on depressive symptoms in year 2. Or stated in another manner, the increase in depressive symptoms over a 1-year period is significantly greater for persons who did not seek help in the interim. The results from the stigma and attitude models further indicate that prior experiences produce reduced stigma for women and greater likelihood of willingness to seek formal mental health care for both men and women. Another important finding is the lack of interaction across place in the buffering effect of prior mental health visits. For persons who have seen a mental health professional in the past year, the impact in buffering the impact of prior depressive symptoms is equivalent across rural locations.

Although these data are suggestive of variability in rural areas, there are limitations in the current study that should be considered. The use of size of place as an indicator of differences across rural places may be problematic. Size of place is most likely an imperfect indicator of contextual effects. It would be advantageous to directly measure characteristics of rural places, such as local unemployment, underemployment, and poverty. This would provide information that would be useful in developing more refined hypotheses regarding the effects of stressors in rural places. It would also permit an investigation of rural variation between places of similar size. For example, it would be of interest to examine characteristics of rural communities that may make residents more or less vulnerable to economic and related stressors. Nonetheless, even using this crude proxy measure, the present study identifies important connections between mental health symptoms, beliefs and attitudes, and variation in rural context.

It should be noted that the present study uses a very limited measure of mental health service use. There is no information on how many times the respondent met with the mental health professional, if they complied with the treatment, or if they were still getting help. Each of these dimensions would provide important insights into the findings reported hi this study. For example, having more of this type of detail could inform the interpretation of the finding regarding the lack of a significant association between help seeking and lowered stigma for men. It should also be noted that this study did not have an experimental design and some caution should be exercised in interpreting the results related to the outcome of mental health treatment, since we can not rule out the potential of selection artifacts.

The findings from this study are consistent with the hypothesis of significant variation in psychological distress and mental health attitudes 
and behaviors across rural settings. The variability of rural places has important consequences for the study of vulnerability and resilience in face of stressors that are increasingly being experienced in these environments. Although the size-of-place measures used in this study are crude indicators of this variability, they provide an important elaboration on studies that have frequently treated this important dimension as a rural/ urban dichotomy. Future research on psychological distress should advance our understanding of patterns of psychological distress by further considering specific characteristics of rural places.

\section{References}

Armstrong, P S., \& Schulman, M. (1990). Financial strain and depression among farm operators: the role of perceived economic hardship and personal control. Rural Sociology $55,475-493$.

Beeson, P, \& Johnson, D. (1987). A panel study of change (1981-1986) in rural mental health status: Effects of the rural crisis. Paper presented at the National Institute of Mental Health Conference on Mental Health Statistics. Denver, CO.

Belyea, M., \& Lobao, L. (1990). Psychosocial consequences of agricultural transformation: The farm crisis and depression. Rural Sociology, 55, 58-75.

Berry, B., \& Davis, A. (1978). Community mental health ideology: A problematic model for rural areas. Orthopsychiatry, 48, 673-679.

Bloomquist, L., Gringeri, C, Tomaskovic-Devey, D., \& Truelove, C. (1993). Work structures and rural poverty. In Rural Sociology Society Task Force on Persistent Rural Poverty (Eds.), Persistent poverty in rural America (pp. 68-105) Boulder, CO: Westview.

Bokemeier, J., \& Tickamyer, A. (1985). Labor force experiences of nonmetropolitan women. Rural Sociology, 30, 51-73.

Brown, D., \& Hirschl, T (1995). Household poverty in rural and metropolitan-core areas of the United States. Rural Sociology, 60, 44-66.

Buckwalter, K. C, Smith, M., Zevenbergen, P, \& Russell, D. (1991). Mental health services of rural elderly outreach programs. Gerontologist, 32, 408-412.

Bultena, G., Lasley, P, \& Geller, J. (1985). The farm crisis: Patterns and impacts of financial distress among Iowa farm families. Rural Sociology, 51, 436-448.

Catalano, R., \& Dooley, D. (1977). Economic predictors of depressed mood and stressful life events in a metropolitan community. Journal of Health and Social Behavior, 18, 292-307.

Catalano, R., \& Dooley, D. (1981). The behavioral costs of economic instability. Policy Studies Journal, 10, 338-349.

Catalano, R. A., \& Dooley, D. (1983). Health effects of economic instability: a test of economic stress hypothesis. Journal of Health and Social Behavior, 24, 46-60.

Conger, R. D., \& Elder, G. H., Jr. (1994). Families in troubled times: Adapting to change in rural America. New York: Aldine de Gruyter.

Coward, R. X, K. L. DeWeaver, K., Schmidt, F, and Jackson, R. (1983). Distinctive features of rural environments: A frame of reference for mental health practice. International Journal of Mental Health, 12, 3-24. 
Davidson, O. G. (1989). Broken heartland: The rise of America's rural ghetto. New York: Free Press.

Dean, A., \& Ensel, W. (1982). Modeling social support, life events, competence and depression in the context of age and sex. Journal of Community Psychology, 10, 92-107.

Dohrenwend, B. P, \& Dohrenwend, B. S. (1974). Social and cultural influences on psychopathology. Annual Review of Psychology, 25, 417-452.

Dooley, D., \& Catalano, R. (1984). The epidemiology of economic stress. American Journal of Community Psychology, 12, 387-409.

Duncan, C. (1992). Rural poverty in America. New York: Auburn House.

Farmer, F, Ilvento, T., \& Luloff, A. (1989). Rural community poverty: A LISREL measurement model. Rural Sociology, 54, 491-S08.

Flaskerud, J., \& Kviz, F. (1982). Resources rural consumers indicate they would use for mental health problems. Community Mental Health Journal, 18, 107-116.

Flax, J., Wagenfeld, M., Ivens, R., \& Weiss, R. (1979). Mental health in rural America: An overview and annotated bibliography. Rockville, MD: National Institute of Mental Health.

Heffernan, W D., \& Heffernan, J. B. (1986). The impact of the farm crisis on families and communities. Rural Sociologist, 6, 160-170.

Hendricks, J., \& Turner H. (1988). Social dimensions of mental illness among rural elderly populations. Internal Journal of Aging and Human Development, 26, 169-190.

Hoyt, D. R., O'Donnell, D., \& Mack, K. Y. (1995). Psychological distress and size of place: The epidemiology of rural economic stress. Rural Sociology, 60, 707-720.

Husaini, B, Neff, J., Harrington, J., Hughes, M., \& Stone, R. (1980). Depression in rural communities: Validating the CES-D Scale. Journal of Community Psychology, 8, 20-27.

Jeffrey, M., \& Reeve, R. (1978). Community mental health services in rural areas: some practical issues. Community Mental Health Journal, 14, 54-62.

Johnson, K. M., \& Beale, C. L. (1992). Natural population decrease in the United States. Rural Development Perspectives, 8, 8-15.

Johnson, D., \& Ortega, S. (1994). A longitudinal analysis of the mental health impacts of the farm crisis. Paper presented at the Fifth International Social Stress Conference. Honolulu, May 25-28.

Kessler, R., Turner, J., \& House, J. (1988). Effects of unemployment on health in a community survey: main, modifying and mediating effects. Journal of Social Issues, 44, 69-85.

Kessler, R., Price, R., \& Wortman, C (1985). Social factors in psychopathology: Stress, social support and coping processes. Annual Review of Psychology, 36, 531-572.

Lahr, M. (1993). Nonmetro poverty rate inches back up. Rural Conditions and Trends, 4 , 48-49.

Lamphere, L. (1992). Structuring diversity: Ethnographic perspectives on the new immigration. Chicago: University of Chicago Press.

Lasley, P (1994). Rural economic and social trends. In R. Conger \& G. Elder (Eds.), Families in troubled times: Adapting to change In Rural America (pp. 57-78). New York: Aldine de Gruyter.

Lichter, D. (1993). Migration, population redistribution, an the new spatial inequality. In D. Brown, D. Field, and J. Zuiches (Eds.). The demography of rural life (pp. 19-46). University Park, PA: Northeast Regional Center for Rural Development. 
Lichter, D., Johnston, G., \& McLaughlin, D. (1994). Changing linkages between work and poverty in rural America. Rural Sociology, 59, 395-415.

Lichter, D., \& McLaughlin, D. (1995). Changing economic opportunities, family structure, and poverty in rural America. Rural Sociology, 60, 688-706.

Lorenz, F., Conger, R., Montague, R., and Wickrama, K. A. S. (1993). Economic conditions, spouse support, and psychological distress of rural husbands and wives. Rural Sociology, 58, 247-268.

Lorenz, F., Saltiel, J., \& Hoyt, D. (1995). Question order and fair play: Evidence of evenhandedness in rural surveys. Rural Sociology, 60, 641-653.

Mirowsky, J., \& Ross, C (1989). Social causes of psychological distress. New York: Aldine de Gruyter.

Naples, N. (1994). Contradictions in agrarian ideology: Restructuring gender, race-ethnicity and class Rural Sociology, 59, 110-135.

Nease, D. E. (1993, September). Mental health issues in rural settings. Kansas Medicine, pp. 246-248.

Newman, J. (1989). Aging and depression. Psychology and Aging, 4, 150-165.

O'Brien, D. J., Hassinger, E. W, \& Dershem, L. (1994). Community attachment and depression among residents in two rural midwestern communities. Rural Sociology, 59, 255-265.

O'Hare, W. P (1988). The rise of poverty in rural America: Population trends and public policy. Washington, DC: Population Reference Bureau.

Ortega, S. T, Johnson, D. R., Beeson, P, \& Craft, B. J. (1994). The farm crisis and mental health: A longitudinal study of the 1980s. Rural Sociology, 59, 598-619.

Patton, H. (1989). Setting the rural health services research agenda: The congressional perspective. Health Services Research 23, 1005-1013.

Pearlin, L., Lieberman, M, Menaghan, E., \& Mullin, J. (1981). The stress process. Journal of Health and Social Behavior, 22, 337-356.

Robins, L. N., \& Regier, D. A. (1991). Psychiatric disorders in America: The epidemiologic catchment area study. New York: Free Press.

Ross, C. E., \& Huber, J. (1985). Hardship and depression. Journal of Health and Social Behavior, 26, 312-327.

Rost, K., Smith, R., \& Taylor, J. (1993). Rural-urban differences in stigma and the use of care for depressive disorders. Journal of Rural Health, 9, 57-62.

Sachs, C. (1983). The Invisible Farmers: Women in Agricultural Production. Totowa, NJ: Rowman and Allanheld.

Tickamyer, A., \& Duncan, C. (1990). Poverty and opportunity structure in rural America. Annual Review of Sociology, 16, 67-86.

Wagenfeld, M., Murray, J., Mohatt, D., \& DeBryn, J. (1994). Mental health and rural America: 1980-1993. An overview and annotated bibliography. Washington, DC: Public Health Service.

Wagenfeld, M., \& Wagenfeld, J. (1981). Values, culture, and the delivery of mental health services in rural areas. In M. Wagenfeld (Ed.), Perspectives on rural mental health. San Francisco: Jossey-Bass.

Wilkinson, K. (1981). The community in rural America. New York: Greenwood.

Wright, S., \& Rosenblatt, P. (1987). Isolation and farm loss: Why neighbors may not be supportive. Family Relations, 36, 391-395. 